Pesquisa e Reflexão em Educação Básica

\title{
Tutoria, projeto de vida e a formação da juventude: desdobramentos da reforma do Ensino Médio
}

Lavínia Maria Silva Queiroz ${ }^{1}$ Meyre-Ester Barbosa de Oliveira²

\begin{abstract}
Resumo:
O trabalho aborda o Ensino Médio em Tempo Integral (EMTI) focalizando a tutoria e o seu papel na construção do projeto de vida, na perspectiva de pensar os desdobramentos dessa política curricular para a formação dos jovens. Tem como base teórica a abordagem do ciclo de políticas (BALL; BOWE, 1992) e a teoria da atuação (BALL; MAGUIRE; BRAUN, 2016). Para a análise dos sentidos e perspectivas sobre a tutoria como proposta curricular do Ensino Médio expõe a análise de entrevistas semiestruturadas realizadas com jovens estudantes, professores e gestão escolar. Os resultados apresentam a enunciação de que o "jovem é o centro da escola", a tutoria se constitui em uma dinâmica de conversa, aconselhamento e acompanhamento articulada a orientação do Projeto de Vida. A política ao ser atuada no contexto da prática está sujeita a ressignificações e reinvenções por parte dos sujeitos envolvidos.
\end{abstract}

\section{Palavras-chave:}

Tutoria. Projeto de Vida. Ensino Médio em Tempo Integral. Políticas. Formação dos Jovens.

\section{Mentoring, life project and youth formation: developments in the reform of High School}

\begin{abstract}
The work here stated addresses Full-time High School (EMTI) focusing on tutoring and its role in the construction of the life project, in the perspective of thinking about the consequences of this curricular policy for the formation of young people. It is theoretically based on the policy cycle approach (BALL; BOWE, 1992) and the theory of performance (BALL; MAGUIRE; BRAUN, 2016). For the analysis of the meanings and perspectives on tutoring as a curricular proposal for high school, it exposes the analysis of semi-structured interviews conducted with young students, teachers and school management. The results present the statement that the "young person is the center of the school", tutoring constitutes a dynamic of conversation, counseling and accompaniment, articulating
\end{abstract}

1 Mestranda em Educação na Universidade Federal do Rio Grande do Norte (UFRN). E-mail: laviniamsq@ hotmail.com. ORCID iD: https://orcid.org/0000-0002-0012-7488.

2 Doutora em Educação, Professora Adjunta da UERN. E-mail: meyrester@yahoo.com.br. ORCID iD: https://orcid.org/00000002-3487-6591. 
the orientation of the Life Project. The policy, when implemented in the context of practice, is subject to reframing and reinvention by the subjects involved.

Keywords: Mentoring. Life Project. Full-time High School. Policies. Youth Formation.

\title{
Mentoría, proyecto de vida y formación de jóvenes: desarrollos en la reforma de la educación secundaria
}

\begin{abstract}
Resumen: El trabajo aborda el Bachillerato a Tiempo Completo (EMTI) enfocando se en la tutoría y su papel en la construcción del proyecto de vida, en la perspectiva de pensar las consecuencias de esta política curricular para la formación de los jóvenes. Teóricamente se basa en el enfoque del ciclo de políticas (BALL; BOWE, 1992) y la teoría del desempeño (BALL; MAGUIRE; BRAUN, 2016). Para el análisis de los significados y perspectivas de la tutoría como propuesta curricular para Bachillerato, se expone el análisis de entrevistas semi estructuradas realizadas con jóvenes estudiantes, docentes y dirección escolar. Los resultados presentan el planteamiento de que "el joven es el centro de la escuela", la tutoría es una dinámica de conversación, asesoría y acompañamiento, articulando la orientación del Proyecto de Vida. La política, cuando se implementa en el contexto de la práctica, está sujeta a un replanteamiento y reinvención por parte de los sujetos involucrados.
\end{abstract}

Palabras clave: Mentoría. Proyecto de Vida. Escuela Secundaria de Tiempo Completo. Políticas. Formación de Jóvenes.

\section{Introdução}

A produção apresentada é o resultado da pesquisa realizada pelas autoras intitulada "A tutoria em uma escola de Ensino Médio em Tempo Integral (EMTI) no município de Mossoró (RN) que teve como objetivo analisar as contribuições da tutoria para o Ensino Médio em Tempo Integral ${ }^{1}$. A pesquisa apresenta reflexões sobre a política de Ensino Médio em Tempo Integral, além disso, traz contribuições para pensar o currículo como produção discursiva e fornece indícios para pesquisas futuras.

A tutoria é um dos recursos inseridos no currículo do Ensino Médio em Tempo Integral que tem como objetivo orientar o jovem, sendo este protagonista de todo processo, a projetar sua vida com base nos cinco itinerários formativos, a saber: Linguagens e suas Tecnologias, Matemática e suas Tecnologias, Ciências da Natureza e suas Tecnologias, Ciências Humanas e Sociais Aplicadas e Formação Técnica e Profissional. Para tanto, essa proposta vem se intensificando na medida em que foi promulgada a Reforma do Ensino Médio (Lei no 13.415/2017).

Para este momento enfatizamos apenas as significações da tutoria no contexto da prática, considerando a perspectiva dos jovens, dos docentes e da gestão sobre a política em questão. Com isso, o nosso objetivo é analisar as contribuições da tutoria para escolas de Ensino Médio em Tempo Integral sob diferentes perspectivas, na perspectiva de compreender os desdobramentos dessa política na formação dos jovens.

Assim, construímos nossos discursos a partir de quatro (4) tópicos principais. Em "A juventude e o Ensino Médio" situamos nosso local de fala e os recortes sobre o que atentamos para esse texto a fim de conduzir o leitor ao que estamos tentando produzir. Seguimos com a explicação do que estamos considerando por política a partir da abordagem cíclica de Sthepen Ball e Richard Bowe (1992). Para mais, descrevemos o processo de pesquisa que envolveu entrevistas semiestruturadas, transcrição e análise destas. E, por fim, propomos a análise da proposta a partir das considerações e perspectivas apontadas pelos sujeitos da pesquisa. 


\section{A juventude e o Ensino Médio}

Com o intuito de nos situarmos enquanto produtores de sentidos na construção deste texto, efetuamos alguns recortes na tentativa de conduzir a leitura desta pesquisa. Assim, entendemos aqui como a juventude, a etapa da vida de um sujeito na condição de juvenil. É importante considerar que na sociedade pós-moderna não é possível uma delimitação fixa dessa condição em função das circunstâncias e contextos nos quais se inserem os sujeitos. Sobre eles, tecemos reflexões com base numa parcela da juventude que se insere no contexto escolar, e especificamente nas instituições públicas de Ensino Médio.

O Ensino Médio desde as últimas décadas atende a uma demanda extensiva de reformas políticas e curriculares, particularmente marcadas pela preocupação com a eficácia e eficiência em face dos baixos índices de rendimento apresentados pelos resultados das avaliações em larga escala. No que se refere à reforma do Ensino Médio, considerando a última mudança temos a Lei 13.415/2017 que altera as Leis no 9.394, de 20 de dezembro de 1996, que estabelece as diretrizes e bases da educação nacional, e 11.494, de 20 de junho 2007, que regulamenta o Fundo de Manutenção e Desenvolvimento da Educação Básica e de Valorização dos Profissionais da Educação, a Consolidação das Leis do Trabalho (CLT), aprovada pelo Decreto-Lei no 5.452, de 1o de maio de 1943, e o Decreto-Lei no 236, de 28 de fevereiro de 1967; revoga a Lei no 11.161, de 5 de agosto de 2005; e institui a Política de Fomento à Implementação de Escolas de Ensino Médio em Tempo Integral.

Esta por sua vez, discorre sobre a ampliação da carga horária do Ensino Médio, mobilizando um currículo estruturado em cinco itinerários formativos preestabelecidos pela Base Nacional Comum Curricular (BNCC), sendo este documento normativo que prevê os conteúdos mínimos a serem adotadas por todas as instituições de ensino.

Pensando nisso, concordamos com Dayrell (2007) ao apontar que as escolas estão cada vez mais inseridas nas ocupações diárias da juventude. E, por mais que maquiados pela visão de uma educação em tempo integral que possa formar os jovens em seus diversos aspectos psicossociais, "a escola perdeu o monopólio cultural, com uma concorrência cada vez maior da cultura de massas e da circulação social de informações (DUBET, 2006 apud DAYRELL, 2007, p. 1117).

Na perspectiva de buscar entender o desenvolvimento da proposta curricular do Ensino Médio em Tempo Integral no contexto escolar, observamos que esse movimento de reformas e mudanças políticas favorece a inserção do terceiro setor na educação pública e, portanto, abrem espaços para as instituições privadas e/ou não governamentais que contribuem com modelos de projetos para o desenvolvimento das políticas apresentadas. Tais instituições atuam

Como patrocinadores e benfeitores, assim como trabalham como contratantes, consultores, conselheiros, pesquisadores, fornecedores de serviços e assim por diante; tanto patrocinando inovações (por ação filantrópica) quanto vendendo soluções e serviços de políticas para o Estado, por vezes de formas relacionadas. (BALL, 2014, p. 181).

Em particular, o Instituto de Corresponsabilidade pela Educação (ICE), atua no Rio Grande do Norte em escolas de Ensino Médio em Tempo Integral com o projeto denominado Escola da Escolha. Nesse caminho, o instituto apresenta em suas propostas curriculares o desenvolvimento do Projeto de Vida do jovem como epicentro para a constituição de uma educação que considera as escolhas dos jovens e favoreça o aprendizado do aluno. Assim, observamos que na Lei 13.415/2017, o termo "projeto de vida" aparece como proposta curricular:

Os currículos do ensino médio deverão considerar a formação integral do aluno, de maneira a adotar um trabalho voltado para a construção de seu projeto de vida e para sua formação nos aspectos físicos, cognitivos e socioemocionais (BRASIL, 2017, art. 34-A § 7으). 
Nesse sentido, o projeto de vida segundo o ICE é

Quem eles querem ser; que valores querem construir e instituir em sua vida como fundamentais; que conhecimentos esperam ter constituído de maneira a ter ampliado e diversificado o seu repertório e que, no conjunto, o apoiarão na tomada de decisões sobre os diversos domínios de suas vidas. (ICE).

Ademais, a Escola da Escolha apresenta vários atores na construção da gestão e organização escolar, dentre eles, destacamos o tutor e o estudante. Neste último encontramos o principal foco do projeto, ou seja, o jovem é o centro da escola. Neste primeiro, encontramos o tutor que é aquele responsável em conhecer e orientar o aluno nas suas relações interativas com/na escola. Nesse sentido, o projeto propõe que a idealização profissional, também nomeada como Projeto de Vida do estudante, seja o objeto principal do tutor, competindo ao jovem o compromisso de atingir essa meta durante o seu percurso escolar.

Também como proposta curricular, na BNCC, o termo "projeto de vida" aparece dezessete (17) vezes, associado a: I) Competências gerais da BNCC, II) Educação integral, III) Escolhas dos anos finais do Ensino Fundamental, IV) Ensino Médio e suas finalidades, V) Compromisso com os jovens, e além disso, existe um tópico na BNCC/Ensino Médio com explicações sobre o projeto de vida (BRASIL, 2018, p. 472).

Tais recorrências aludem a intencionalidade e o interesse político na repercussão da ideia de que o jovem do Ensino Médio pode delinear seus estudos a partir de seus planos e projetos de vida, propagando a contraditória proposta de que o aluno é protagonista de suas próprias escolhas.

No que se refere às escolhas e a proposta do projeto de vida dos jovens, podemos perceber que a perspectiva apresentada justifica algumas questões propostas pela/na política curricular. $O$ instituto evidencia a sua concepção de políticas, compreendendo-as como propostas que devem atender a resolução de problemas, como "uma ciência de entrega, uma resposta ao 'desafio da produtividade"” (BABER, 2007, apud BALL et al., 2016, p. 111), e, nessa perspectiva, como afirma Taylor (et al., 1997, p. 5 apud BALL et al., 2016, p. 13) "descrevem como a '[...] única resposta plausível para [as] mudanças sociais e econômicas".

Logo, posterga a participação e disputas existentes no processo da política que podem "estar fora da máquina formal da elaboração de política oficial" (OZGA, 2000, p. 113 apud BALL et al., 2016, p. 13). Dito isso, observamos a articulação do projeto de vida com a flexibilização curricular, prometendo ao estudante, o direcionamento das atividades para o seu projeto, entretanto, estes devem ser definidos a partir de limitadores fixados pela BNCC/Ensino Médio, são eles, os itinerários formativos.

Motivados por essa análise, refutamos a ideia de flexibilização curricular a partir dos projetos de vida, uma vez que estes são pré-fixados pelos próprios documentos e idealizam um projeto "como se as experiências educativas estivessem obrigatoriamente sintonizadas com um futuro pré-programado no presente" (LOPES, 2019, p. 69).

Ainda mais, os cadernos de práticas apresentados no guia de implementação da BNCC ${ }^{2}$ enfatizam mais um direcionamento para os projetos de vida, considerando que a "projeção para o mundo do trabalho é um dos focos do projeto de vida" (BRASIL, 2018), logo, percebemos a intencionalidade e a prescrição dos documentos para os estudantes, assim, entendemos que

Tal enfoque pode apenas estar tentando antecipar decisões, submeter experiências imprevistas a um dado projeto de futuro que não faz obrigatoriamente sentido para as singularidades juvenis, mas está submetidos aos anseios de grupos sociais que supõem saber dizer como o futuro dos jovens deve (e pode) ser. (BORGES; LOPES; SANTOS, 2019, p. 69).

2 Disponível em: http://basenacionalcomum.mec.gov.br/implementacao/praticas/caderno-de-praticas/aprofundamentos/ 200-projeto-de-vida-ser-ou-existir. Acesso em: 13 jan. 2020. 
Portanto, a projeção do futuro dos jovens viabiliza a fixação de identidades, e, pensando com Lopes (2019b, p. 243) numa perspectiva discursiva "ressaltamos a incapacidade de regulação total: os sentidos sempre irrompem", para tanto, reside à impossibilidade de um futuro pré-programado que supere todas as demandas e subjetivações do indecidível.

Assim, a projeção de identidades não é possível tendo em vista que elas são contingentes e se constituem a partir do Outro, logo estão sujeitas ao "devir". Ademais, as identidades são "as posições que o sujeito é obrigado a assumir” (HALL, 2009, p. 112) em vista das representações as quais lhes são contrárias. Nesse sentido, essas posições são "construíd[os] ao longo de uma 'falta', ao longo de uma divisão, a partir do lugar do Outro" (HALL, 2009, p. 112, grifos do autor). Isto é, são projeções provocadas numa disputa de posições que incidem na contrariedade do que está previsto.

Sendo assim, as demandas dos itinerários formativos, bem como a ênfase no mercado de trabalho se constitui por identidades (ou, como está sendo chamado, de projetos) que se estabelece na falta ou na exclusão daquilo que é diferente do previsto.

Enfim, a proposta do projeto de vida como solução para escolhas e protagonismo do jovem contraria os princípios norteadores do currículo do Ensino Médio - a BNCC, pois a base compreende uma organização por competências comuns a todos os estudantes e, para, além disso, as escolhas possíveis ao estudante limitam-se ao cardápio proposto pelos itinerários formativos.

Além do mais, expõe em suas concepções políticas a pretensão de uma proposta curricular que presume resultados e respostas como um mercado de entrega, possibilitando, dentre muitas tensões na política, a competitividade e a demanda de funções aos profissionais docentes.

\section{A política de Ensino Médio em Tempo Integral enquanto processo cíclico}

Neste tópico, buscamos compreender a política a partir do que Ball e Bowe (1992) desenvolve como ciclo contínuo de políticas, compreendendo que a política é um processo cíclico, além de compreender que esta "não é um documento, mas sim uma entidade social que se movimenta e se modifica” (LIMA; LUCE; SOUZA, 2018, p. 3), ou seja, a política não é um texto produzido em uma relação hierárquica, mas sim, uma construção cíclica modificada nos/pelos diversos espaços que ela perpassa. "Essa abordagem destaca a natureza complexa e controversa da política educacional, enfatiza os processos das micropolíticas e a ação dos profissionais que lidam com as políticas no nível local" (MAINARDES, 2006b, p. 49), fazendo isto a partir de três contextos - contexto da influência, contexto da produção de textos e contexto da prática, que possuem relação entre si e não estão dispostos em uma sequência temporal ou ordinária (MAINARDES, 2006a).

Nesse momento queremos tratá-la como contexto da prática, considerando a partir de Ball (apud OLIVEIRA, 2015, p. 42) "que é também nas instituições educacionais que as políticas de currículo se constituem, por meio de disputas e negociações de saberes e poderes que legitimam e hegemonizam provisoriamente os sentidos".

Advogamos que nesses espaços as políticas são ressignificadas, isto é, possibilitam outras versões e constroem sentidos a partir da convivência escolar e das demandas de cada sujeito. Nessa perspectiva, compreendemos que "o contexto da prática é onde a política está sujeita à interpretação e recriação e onde a política produz efeitos e consequências que podem representar mudanças e transformações significativas na política original” (BALL apud MAINARDES, 2006a, p. 53).

Concebendo que os atores da política possibilitam mudanças na política, mesmo que na recriação no contexto da prática, prosseguimos a análise em uma instituição, a qual intitulamos por Escola de Ensino Médio em Tempo Integral para resguardar a identidade dos envolvidos. 


\section{Delineando o percurso metodológico}

A instituição na qual desenvolvemos a pesquisa consiste em uma das escolas de ensino em tempo integral do Rio Grande do Norte. Estas constam no Diário Oficial/Rio Grande do Norte, na Portaria no 1245/2017 - SEEC/GS apresentadas pela Secretaria de Estado da Educação e da Cultura do Rio Grande do Norte (SEEC/RN) com o número de dezoito (18) escolas para receber o projeto.

A instituição, a qual preservamos sua identidade, está situada em um bairro que abriga oito mil quatrocentos e noventa e cinco (8.495) habitantes, cuja maioria são jovens e mulheres. Apesar disso, neste bairro existe apenas uma escola de ensino médio.

A escola em questão é uma Instituição de Educação Básica desde 15 de março de 1965. O seu Ato de Autorização foi publicado no Diário Oficial do Estado do Rio Grande do Norte em 1980. A instituição atende a etapa de Ensino Médio e, em 2017, iniciou a oferta na modalidade de Tempo Integral.

Realizamos a entrevista na referida escola onde resguardamos a identificação dos sujeitos e ressaltamos que a gravação é consentida pelos entrevistados com autorização da utilização dos dados para fins acadêmicos. Estes esclarecimentos foram apresentados junto ao Termo de Consentimento Livre Esclarecido (TCLE). Para mais, enfatizamos que as entrevistas foram realizadas em março de 2019 e o processo de transcrição ocorreu em igual período. Assim, contamos com a colaboração de dois profissionais que atuam na administração pedagógica, sendo permitida a gravação por apenas um deles, mesmo assim, este último nos concebeu um diálogo sobre o assunto, a partir do qual utilizaremos para apresentar alguns dados sobre a tutoria na escola. Além deles, participaram também dois docentes e uma aluna.

No que se refere à caracterização dos participantes docentes, um deles é professor de disciplina da base comum e participa do quadro de professores que atuam nas aulas do Projeto de Vida. O outro docente também ministra disciplina na base comum e, além disso, coordena uma das áreas de ensino disposto dentre os cinco (5) itinerários formativos propostos pela nova organização curricular.

Identificaremos os sujeitos entrevistados a partir de uma nomenclatura alfanumérica utilizando a primeira letra das funções exercidas na escola pelos mesmos e ordem crescente para os algarismos indo-arábicos. Portanto, a nomenclatura referida aos professores durante o trabalho será, respectivamente, $\mathrm{P} 1$ e P2, além disso, no que se refere ao profissional que atua na gestão pedagógica e a aluna entrevistada, nos remetemos a elas, nesta ordem, como G1 e A1.

Para transcrição dos áudios das entrevistas, utilizamos como auxílio tecnológico o aplicativo VoiceMeeter ${ }^{3}$ Output que reproduz o som em texto escrito a partir do site https://dictation.io/, portanto o programa foi fator importante para uma rápida transcrição. Conquanto, foi necessário ouvir novamente o áudio para corrigir possíveis erros e falas não detectadas pelo aplicativo, bem como para uma melhor apreensão dos sentidos.

Neste momento, utilizamos como ferramenta para revisão do texto o site https://otranscribe.com/, o qual que permite realizar o controle do áudio sem que seja necessário abrir um documento do Microsoft Word com auxílio do arquivo de áudio no Windows Media Player e oscilar entre os dois para ouvir e acompanhar a transcrição.

A partir deste último site, o usuário tem o arquivo e o documento em uma única tela, o que possibilita o comando do som pelo próprio teclado. Por exemplo, para acionar o comando pause não é necessário clicar com o mouse, basta clicar na tecla esc, outra ferramenta que auxilia o processo é o acionar do play depois de um pause, pois, o software antecipa alguns segundos do arquivo para que o usuário possa acompanhar o que estava ouvindo e o que virá a ouvir.

\footnotetext{
3 "VoiceMeeter é um aplicativo de mixagem de áudio dotado de dispositivo de áudio virtual usado como Virtual I / O para misturar e gerenciar quaisquer fontes de áudio de ou para qualquer dispositivo ou aplicativo de áudio". Disponível em: https://www.vb-audio. com/Voicemeeter/. Acesso em: 23 mar. 2019.
} 
No tocante a análise das entrevistas, buscamos conhecer os sentidos produzidos pelos sujeitos entrevistados, mediante o exame das respostas em seu conjunto. Portanto, não há uma preocupação em apresentar as falas conforme a sequência das perguntas propostas, uma vez que compreendemos a entrevista como uma produção discursiva na qual entrevistador e entrevistado produzem sentidos, nesse encontro que é intersubjetivo.

\section{A tutoria no Ensino Médio em Tempo Integral: uma análise sob a perspectiva dos diferentes sujeitos}

Aproveitaremos este momento para compreender a construção dos sentidos da tutoria no desenvolvimento do EMTI, concebendo o contexto da prática como "potência de participação na constituição das políticas, que são produzidas por processos de tradução/negociação em múltiplos contextos e por diferentes sujeitos" (OLIVEIRA, 2015, p. 46).

É nesse cenário que a política é "encenada (colocada em cena, em atuação) (ao invés de implementada)" (BALL; BRAUN; MAGUIRE, 2016, p. 13). Esta atuação envolve 'interpretações de interpretações' (KEMMIS; RIZVI, 1987 apud BALL; BRAUN; MAGUIRE, 2016, p. 14).

Assim, também interpretamos as falas dos entrevistados concebendo-os como sujeitos que se constituem "atores e sujeitos, sujeitos e objeto da política" (BALL; BRAUN; MAGUIRE, 2016, p. 13), isto será exposto na condição de salientar as contribuições deles para a política de EMTI.

Para começar, realizamos um levantamento dos sentidos atribuídos ao termo tutoria pelos diversos entrevistados com o objetivo de perceber as significações sobre a política. Com isso observamos o uso dos significantes "conselheiro, psicólogo, amigo, pai, mãe, padrinho, irmão, anjo da guarda" para caracterizar o tutor. Estes termos estão geralmente associados às palavras "acompanhamento, aconselhamento e conversa".

Sobre tais discussões, elaboramos um gráfico para quantificar a repetição dos significantes "acompanhar", "conselho"5 e "conversar"6 presentes nas falas dos quatro entrevistados, e obtivemos o seguinte resultado:

Gráfico 1 - Incidência dos Significantes: acompanhar, conselho e conversa

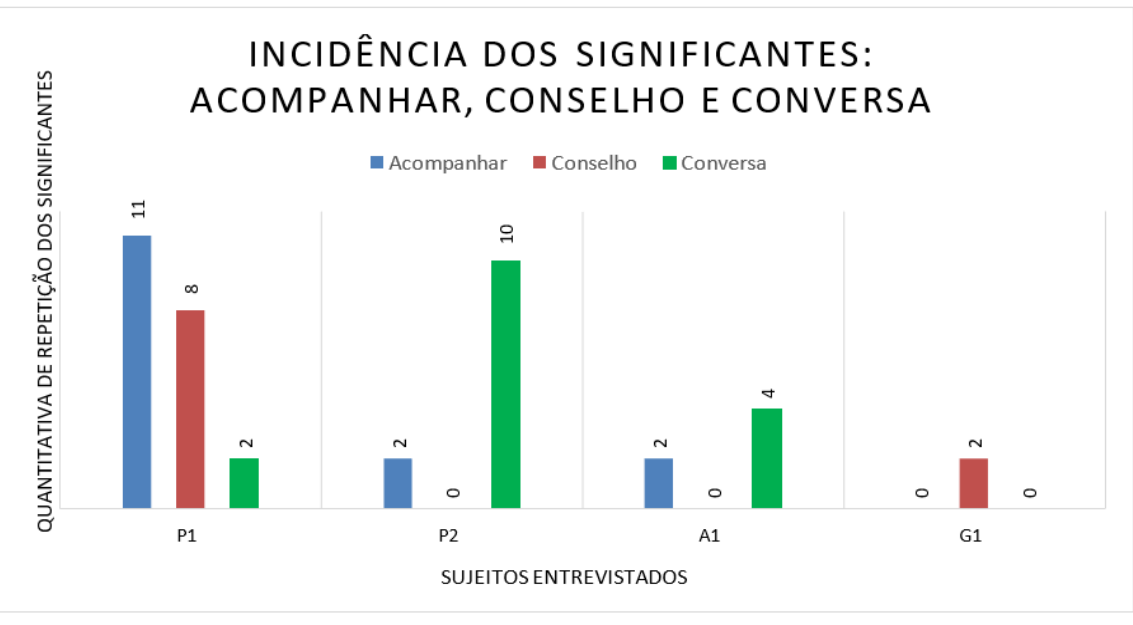

Fonte: Elaborado pelas autoras.

4 Consideramos as seguintes derivações da palavra "acompanhar": acompanhamento, acompanhando e acompanhado.

5 Consideramos as seguintes derivações da palavra "conselho": aconselhar, aconselhamento, conselheiro e aconselham.

6 Consideramos as seguintes derivações da palavra "conversar": conversa e conversarmos. 
Na fala de P1 encontram-se mais presentes os significantes "acompanhar" e "conselho", estes, em sua maioria, relacionam-se à frase "trilhar os caminhos que consideramos correto". Já nos discursos de P2 a palavra "conversa" é anunciada com mais frequência e se apresenta como papel do tutor conversar com os tutorandos sobre diferentes aspectos, de acordo com suas necessidades.

De acordo com A1 há um equilíbrio entre os termos "acompanhar" e "conversa" inclinando estes sentidos para a relação que deve existir entre os envolvidos. Por fim, para C2, o tutor é visto como alguém que aconselha e é fundamental em razão da inexistência de outros profissionais qualificados para realizar um acompanhamento psicológico.

Em resumo, o significante "acompanhar" aparece 15 vezes, "conselho", 10 vezes e "conversa", 16 vezes. Tais resultados apresentam a enunciação de que a tutoria se constitui em uma dinâmica de conversa, aconselhamento e acompanhamento.

Como aponta P1 "[...] o objetivo da tutoria é tentar direcionar o aluno para o caminho considerado correto: o caminho dos estudos, não se envolver com pessoas erradas, não se envolver com coisas erradas [...]". Corrobora também com a ideia de P2, afirmando ser a tutoria "[...] a questão de acompanhamento" ou mesmo, como apresenta A1, "a tutoria é só uma ajuda, porque às vezes o aluno tem dificuldade em se expressar, às vezes em um conteúdo, ou quer conversar alguma coisa sobre a didática que não está entendendo, ou o professor".

Sobre a significação de tutoria apresentada pela instituição, é explícita a delimitação sobre o que é o que não é a tutoria. Assim, de acordo com o ICE (2015a, p. 21) a tutoria é "oferta de apoio para reflexão e orientação das múltiplas aprendizagens do estudante; Atuação generosa com claros limites de atuação pautada pela ética profissional" e não é o "estabelecimento de uma relação familiar [...]; julgamento das escolhas, dos valores, e das decisões do tutorado, nem da sua família; sessão psicoterapêutica; convivência confusa e desordenada em que não há respeito [...]".

Ainda que os sentidos "sessão psicoterapêutica" e "existência de uma relação familiar" sejam abordados nos cadernos de formação, disponibilizados pelo ICE, como características que não devem ser significadas à função do tutor, observamos na fala dos sujeitos a relação da tutoria com estes sentidos.

Mesmo assim, queremos explicitar a nossa intenção de anunciar a interpretação da política e das demandas contingenciais existentes no contexto da prática - que delineamos nessa construção até o dado momento -, a fim de perceber as permutas provocadas pelos atores nos diversos espaços do ciclo contínuo da política, os quais possibilitam o envolvimento e a atuação dos sujeitos.

Reforçando que "colocar a política em prática é um processo criativo, sofisticado e complexo" (BALL; BRAUN; MAGUIRE, 2016, p. 21), consideramos assim como Moore (2006, apud BALL; BRAUN; MAGUIRE, 2016, p. 64) que "essas dimensões afetivas podem amortecer as tensões do cotidiano escolar e habilitar a equipe para dar 'condições meteorológicas' à tempestade da política".

A esse respeito, o tutor se mostra como alguém que está disponível ao aluno "para ouvir e na medida do possível aconselhar e se possível interferir na família" (P1, 2019), assim como conversar com os alunos sobre problemas pessoais e acadêmicos. Como afirma o entrevistado P2 ao se referir aos alunos: "se quiser conversar comigo, no momento em que eu esteja disponível [...] eu estarei aqui para isso [...]".

No que se refere aos critérios para ser constituído um tutor, foram levantados os seguintes princípios: ser funcionário da escola e dispor de um diploma de Ensino Superior. Sobre isto, P1 discorda, e justifica que: "temos aqui na nossa escola um porteiro, que com suas palavras já tirou alunos nossos/ex-alunos do caminho das drogas, do mau caminho, vamos dizer assim". Seu argumento leva em conta que

Todos os membros da escola, eles orientam nossos alunos para que eles possam trilhar o caminho que nós acreditamos ser correto, que é ser acima de tudo, independente da profissão escolhida, acima de tudo eles venham a ser cidadão de bem. (P1, 2019). 
Em contrapartida, inferimos, de acordo com as falas dos entrevistados e com a proposta apresentada pelo ICE, que para orientação acadêmica destes tutorandos se faz necessária uma formação, na medida em que a tutoria tem uma dimensão acadêmica que se articula ao Projeto de Vida. Compreendemos então, a necessidade do critério do Ensino Superior, logo os tutores são licenciados e podem realizar um acompanhamento acadêmico deste aluno, não se resumindo apenas ao papel de orientar os alunos "para o caminho do bem".

Diante disso, o entendimento de um futuro pré-programado ou mesmo um projeto do futuro por outros sujeitos que possam orientar os alunos para o que se intitula como "caminho do bem" nos remete à reflexão de que as decisões futuras da juventude estão sendo antecipadas pelo tutor, e, mais que isso, confere ao tutorando um caminho permeado de interesses de grupos específicos (LOPES, 2019). Ou seja, acreditando que é possível programar o futuro no presente e submetê-lo aos interesses e prerrogativas de outrem.

Ainda no que se refere ao processo de escolha dos tutores, cumpre esclarecer que é realizada uma feira, denominada pelos entrevistados de "feirão" (P2) e, também, por "feira dos tutores" (P1, A1). A organização física da feira é apresentada pelo entrevistado da seguinte forma:

Sobre a estrutura é colocada uma espécie de bancada em uma extremidade do refeitório e nessa bancada são disponibilizadas fichas com os nomes dos tutores. Ao disponibilizar as fichas, antes disso, a coordenação explica o que vem a ser a tutoria e explica como é feito a escolha, como eles devem fazer a escolha, no caso, por afeição ou algo dessa natureza e falam que é limitado o número de vaga para cada tutor. Após isso é pedido para que os alunos se dirijam até essa bancada e procurem o professor ou qualquer outro funcionário que queira que seja ser seu tutor. (P1, 2019).

No mais, percebe-se que a estrutura apresentada, no qual os professores (ou mesmo seus nomes) estão dispostos em uma bancada para a escolha do aluno, é similar ao sistema mercadológico, que vem progressivamente sendo transplantado para dentro da escola.

Assim, os professores passam a ser "encenadores de técnicas, que se destinam a tornar os alunos visíveis e produtivos" (BALL; BRAUN; MAGUIRE, 2016, p. 105). E neste caso se empenham em negociar com os alunos estratégias para um bom rendimento nas notas, já que "se tiver um rendimento muito baixo a gente já vai chegar junto desse aluno para poder, para fazer, para meio que abrir a mente dele, para ele poder dar continuidade a isso daqui, que estude um pouco mais" (P2, 2019). Também são realizados "encontros ordinários, que é ao final de cada bimestre, para ver como é que estão as notas, um levantamento (um acompanhamento) para ver o rendimento dele" (P1, 2019).

Essa relação contribui para fortalecer "um sistema de regulação", ou seja, "o micromundo de interações da sala de aula e os objetivos de nível macro de padrões e realizações" (JONES, 2003 apud BALL; BRAUN; MAGUIRE, 2016, p. 109) da política de EMTI.

Para Barber (2007, apud BALL; MAGUIRE; BRAUN, 2016, p. 111) essa interação é entendida como "deliverolgy, uma ciência de entrega, uma resposta ao desafio da produtividade". Tal perspectiva produz no tutor uma tensão no que se refere a acompanhar o seu aluno e induzi-lo a ser produtivo, apresentando boas notas e bom comportamento, constituindo o que Ball, Braun e Maguire (2016, p. 111) afirmam como "escolaridade como performances (desempenhos)".

Sobre isto, Foucault (1979, p. 187 apud BALL; BRAUN; MAGUIRE, 2016, p. 113) aborda como "poder disciplinar", o que "impõe sobre aqueles sujeitos a um princípio de visibilidade obrigatório... é o fato de ser constantemente visto, de ser sempre capaz de ser visto que mantém o sujeito disciplinado em suas sujeições" (BALL; BRAUN; MAGUIRE, 2016, p. 113).

Portanto, percebemos que a proposta da tutoria realça a "performatividade" dos docentes, dado que as recentes reformas educacionais viabilizam as mudanças curriculares dos profissionais da educação. Assim,

O currículo tem sido modificado com a introdução de novas abordagens - currículo baseado em competências - acompanhando as orientações de Agências Internacionais, tais como 
Banco Mundial, Organização para a Cooperação e Desenvolvimento Econômico (OCDE), Banco Interamericano de Desenvolvimento (BID) etc. (BALL et al., 2013, p. 10).

O que para Ball et al. (2013, p. 13) amplia as demandas decorrentes das políticas e, embora se fale em autonomia e descentralização, as exigências e cobranças se intensificam e recaem sobre os docentes. Essas transformações são influenciadas pela onda neoliberal que promove a competição das escolas públicas em busca de uma "privatização endógena e exógena".

Quando se trata da "privatização endógena" Ball et al. (2013, p. 13) enfatiza a Nova Gestão Pública (NGP) conceituando-a como "uma gestão performática (baseada no desempenho) e sistemas de prestação de contas e responsabilização (accountability) têm colonizado os sistemas educacionais em todo o mundo".

Nesse processo de privatização, os professores assumem novas exigências, logo, possuem mais responsabilidades, que são cada vez mais prescritas e controladas pela NGP, contribuindo significativamente para intensificação do trabalho docente, que "está diretamente ligada ao aumento do gerencialismo e da performatividade" (BALL et al., 2013, p. 15), bem como,

Hargreaves (1994, p. 118) descreve com um estado individual e institucional de '[...] sobrecarga crônica e persistente, que reduz áreas de discernimento pessoal, inibe o envolvimento e o controle sobre o planejamento de longo prazo, e promove a dependência de especialistas e de materiais produzidos externamente'.

É nestas condições que a tutoria se insere, posto que o projeto não apresenta horário exclusivo para orientações, uma vez que não se constitui como uma disciplina. Nesses termos, a tutoria é uma atividade realizada pelos professores sem que haja um horário específico para tal, em qualquer horário que ele esteja na escola, seja no almoço, no intervalo ou no momento de descanso.

No que concerne ao desempenho da tutoria, o entrevistado P2 nos revela que "nos corredores mesmo, já é um momento de conversa entre professor e aluno e quando o professor sente alguma deficiência em determinada disciplina do aluno, a gente vai chegar junto" (2019).

Para mais, as políticas como apresentadas desenvolvem-se, em sua maioria, mediante busca de parcerias e colaborações de "atores estatais e não estatais, públicos/privados e lucrativos/sem fins lucrativos" (BALL et al., 2013, p. 20) para "o desenvolvimento e difusão de políticas públicas e sociais" e, assim, a performatividade que se apresenta nas metas e centralidades da política se constituem nas instituições públicas, refletindo no trabalho docente.

A respeito disto, é nítida a intervenção da instituição apresentada na formação dos professores, na medida em que os funcionários da escola só podem vincular-se à instituição depois de passarem pelas formações que tomam como referência os cadernos de formação do ICE.

Os cadernos são concebidos por P1 como "uma espécie de bíblia, um conjunto de cadernos que trazem/que mostram o passo a passo do que é o Integral e em um desses cadernos traz o que vêm a ser a tutoria". A prescritividade realçada por P1 é visivelmente ressignificada por P2 ao afirmar que "eu não sou um robô que trabalha apenas para trabalhar aquilo que tá sendo imposto nos cadernos do ICE".

Além disso, outro aspecto que compõe o processo político são as relações emocionais que a política reflete, "elas podem ameaçar ou perturbar a autoestima, o propósito e a identidade. Elas podem entusiasmar, deprimir ou afligir” (BALL; BRAUN; MAGUIRE, 2016, p. 21). Isso é perceptível na fala dos entrevistados no momento em que perguntamos sobre como eles se sentem durante $o$ processo de escolha do tutor:

Para P1 (2019),

A palavra é responsabilidade [...] a princípio você trabalha a parte de rendimento do aluno, o comportamento em sala de aula, mas ao mesmo tempo, você mexe com as emoções do aluno, 
já que ele pode trazer situações problemas da sua vida pessoal, que é o que normalmente acontece. Então, a preocupação é dá um conselho que possa incomodar em casa ou não agradar em casa, e isso possa trazer um retorno nada agradável para o aluno e também para escola, [...]. Então, é algo que... não sei se a palavra correta é preocupante, mas é muita responsabilidade, é algo a se pensar. Tem que medir bastante as palavras, medir bem as palavras antes de aconselhar um aluno quando ele traz um problema pessoal.

A fala de P2 (2019) também reflete as tensões que perpassam o exercício da tutoria, conforme exposto a seguir:

Eu fico ansioso (risos), porque existem alguns alunos que você fica: 'Poxa ${ }^{7}$, eu quero, preciso ajudar esse cara!' Eu sei que ele está precisando de ajuda... digamos que ele está... você percebe no momento do acolhimento. [...] No processo da feira eu fico super ansioso, 'Porque será que essas pessoas vão me escolher?'. [...] E é isso, eu fico muito ansioso, e eles, com certeza, também. 'Poxa, eu vou escolher você como meu tutor'.

Em relação a escolha do tutor, G1 (2019) comenta:

Eu vejo assim, porque a maioria dos funcionários, professores já são conhecidos e só o primeiro ano que fica um pouco assim. Eu acredito que o ideal é passar mais ou menos umas duas semanas conhecendo o quadro de professores e de funcionários para depois escolher o seu tutor. [...] O ideal, eu acho, é que antes dessa feira tem que ter o conhecimento, umas duas semanas conhecendo, para depois ele escolher, para não ficar mudando e às vezes ele quer mudar e fica intimidado né [...].

Contudo, as interpretações e tensões provocadas pela tutoria contribuem para ressignificações da política no contexto da prática. Estas se fazem sem intenção, ou mesmo se produzem por ações que não conseguimos controlar, mas que são fruto do processo político, que simultaneamente nos inibe e produz sentidos que podem não estar explícitos nos discursos que circulam na escola.

Destacamos também a íntima relação da tutoria com a modalidade de ensino em tempo integral, em virtude do tempo que o aluno passa na escola. $O$ projeto se revela significativo, visto que a sua ausência no ano em que teve início o tempo integral, foi mencionado como um dos fatores que provocou a evasão dos alunos.

Como afirma P2: "2017 foi um ano de implantação, teve muita dificuldade e a tutoria não iniciou como deveria [...] e acabamos perdendo aluno por falta dessa tutoria, que é importantíssima”. A relevância da tutoria como suporte para o ensino integral é igualmente realçada por G1 que demonstra a importância da tutoria "na falta de um psicólogo na escola".

Ademais, a correlação da tutoria com o Projeto de Vida é evidente já que "quando o tutor é escolhido pelo aluno, então um dos seus questionamentos para o aluno é conhecer o projeto de vida dele, para que possa orientar/direcionar melhor esse aluno" (P1, 2019), e "esse acompanhamento, e essa preocupação do professor, eu acho que ele 'meio que acaba acordando para vida" (P2, 2019).

Portanto, ao ser acompanhando por um tutor, o aluno deve ser estimulado no sentido de "nunca desacreditar! Pelo contrário, sempre fazer com que ele acredite que é possível e, orientando para que ele possa chegar/possa alcançar o seu projeto" (P1, 2019). Por outro ponto de vista, o elo da tutoria com o Projeto de vida se dá quando o aluno "às vezes sonha alguma coisa e acha que não vai realizar esse sonho, ele pode conversar e tirar dúvida com o tutor" (A1, 2019).

Em face do exposto, argumentamos que a tutoria como projeto desenvolvido no Ensino Médio em Tempo Integral no contexto da prática modifica a política e contribui para sua constituição. Assim, podemos compreendê-la como um processo que "não se encerra na produção dos

7 Poxa é uma expressão utilizada informalmente para designar situações que provocam espanto, ou servem também para exprimir um estado emocional, bem como um estado de espírito ou sensação. Disponível em: https://www.significadosbr.com.br/poxa. Acesso em: abr. 2019. 
documentos oficiais, não sendo, portanto, um processo linear e hierárquico, mas ao contrário constitui-se em múltiplos contextos, pela articulação de diferentes sujeitos e em tempos concomitantes" (OLIVEIRA, 2015, p. 42).

\section{Algumas considerações}

A tutoria nas escolas de Ensino Médio em Tempo Integral é uma micropolítica significativa no projeto desenvolvido na escola em colaboração com o Instituto de Corresponsabilidade pela Educação (ICE). Portanto, ao investigarmos as contribuições da tutoria para o desenvolvimento da proposta de EMTI e seus desdobramentos para a formação dos jovens que frequentam o ensino médio, a partir da análise das entrevistas, foi possível compreender as ressignificações políticas presentes no contexto escolar, enfatizando o contexto como possibilidade de reinvenção e criação da política.

Construímos um debate com autores pós-críticos sobre a produção das políticas e sobre a construção do currículo. Assentamos sobre as impossibilidades curriculares apresentadas pelos documentos, considerando que alguns limitadores como itinerários formativos e as competências inviabilizam as escolhas dos jovens, uma vez que há o controle dos possíveis projetos por meio dos limitadores.

Com isso, destacamos a política como um processo de ressignificação que viabiliza o "tornar-se" política e ainda contribui para o desenvolvimento desta. Ademais, ao ponto que a tutoria tangencia a política em diversos contextos e perspectivas, ela ecoa a pretensão política das reformas que vêm se intensificando na contemporaneidade. Contribui na projeção da performatividade nas escolas, coagindo a dedicação dos professores para além da sua profissão, patenteando diversas profissões em uma.

Além disso, os resultados das pesquisas reforçam uma concepção de um devir para a juventude que precisa ser controlado, mediante a realização de um projeto de vida, que supostamente os colocaria no "rumo certo" de suas vidas, como se o futuro fosse algo previsível e passível de controle. Construindo uma perspectiva de que os jovens precisam de alguém para delinear os caminhos aos quais pretendem trilhar. Assim, apesar do discurso político apontar o jovem como centro e protagonista, as ações são pautadas para um alinhamento da formação com as demandas mercadológicas.

Por que supor que a juventude pode ou deve antecipar seu projeto de vida, como se as experiências educativas estivessem obrigatoriamente sintonizadas com um futuro pré-programado no presente, ao invés de atenderem demandas e expectativas urgentes da vida dos estudantes hoje? Tal enfoque pode apenas estar tentando antecipar decisões, submeter experiências imprevistas a um dado projeto de futuro que não faz obrigatoriamente sentido para as singularidades juvenis, mas está submetido aos anseios de grupos sociais que supõem saber dizer como o futuro dos jovens deve (e pode) ser. (LOPES, 2019, p. 68-69).

É instigante e necessário evidenciar e construir debates que enfoquem a juventude e os processos escolares. Ainda assim, certas de que não podemos responder a todas as especulações que surgem durante o processo da escrita, nos detemos no foco da pesquisa. Entretanto, nos questionamos, em muitos momentos durante este percurso, sobre as (im)possibilidades das políticas de tempo integral para a significação do que entendemos por juventude, por escola, educação, currículo e formação.

Ademais, tentamos explorar nesta pesquisa a tutoria como política que se desenvolve em meio a contextos e demandas individuais e coletivas que são lidas a partir das subjetividades dos jovens. Fizemos isso a fim de contribuir com as pesquisas e instigar os leitores e interessados no tema a compreenderem, mesmo que não consigamos fazê-la em sua totalidade, a tutoria numa perspectiva de ensino em tempo integral. 


\section{Referências}

BALL, Stephen J.; BAILEY, Patrick; MENA, Paula; MONTE, Pablo Del; SANTORI, Diego; TSENG, Chun-Ying; YOUNG, Helen; OLMEDO, Antonio. A constituição da subjetividade docente no Brasil: um contexto global. Revista Educação em Questão, Natal, v. 46 n. 32, p. 9-36, maio/ago. 2013.

BALL, Stephen J.; MAGUIRE, Meg; BRAUN, Annette. Como as escolas fazem as políticas: atuação em escolas secundárias. Ponta Grossa: Editora UEPG, 2016. 230 p.

BALL, Stephen J. Educação Global S. A.: novas redes de políticas e o imaginário neoliberal. Tradução de Janete Bridon. Ponta Grossa: UEPG, 2014. 181 p.

BARBER, Michael. Instruction to Deliver: Tony Blair, the public services and the challenge of delivery. London: Methuen, 2007.

BOWE, RICHARD; BALL, Stephen; WITH GOLD, A. Reforming education \& changing schools: case studies in Policy Sociology. London: Routledge, 1992.

BRASIL. Base Nacional Comum Curricular (BNCC) do Ensino Médio. Educação é a Base. Brasília, DF: MEC/CONSED/ UNDIME, 2018.

BRASIL. Lei no 13.415, de 16 de fevereiro de 2017. Institui a Política de Fomento à Implementação de Escolas de Ensino Médio em Tempo Integral. Brasília, DF, 16 fev. 2017a. Disponível em: http://www.planalto.gov.br/ccivil_03/_ato20152018/2017/lei/l13415.htm. Acesso em: 12 jan. 2020.

DAYRELL, Juarez. A escola "faz" as juventudes? Reflexões em torno da socialização juvenil. Educação e Sociedade, Campinas, v. 28, n. 100 - Especial, p. 1105-1128, out. 2007.

FOUCAULT, Michel. Discipline and punish: the birth of the prison. London: Peregrine Books, 1979.

HALL, Stuart. Quem precisa da identidade? In: SILVA, Tomaz Tadeu da (org.). Identidade e diferença: a perspectiva dos estudos culturais. Trad. de Tomaz Tadeu da Silva. Petrópolis: Vozes, 2009. p. 103-133.

INSTITUTO DE CORRESPONSABILIDADE PELA EDUCAÇÃO (ICE). Modelo Pedagógico, Metodologias de Êxito da Parte Diversificada do Currículo: Práticas Educativas. 2. ed. Recife: [s.n.], 2015. 32 p.

JONES, Ken. Education in Britain: 1994 to the presente. Cambridge: Polity, 2003.

LIMA, Laudirege Fernandes; SOUZA, Bruna de; LUCE, Maria Beatriz. A abordagem do ciclo de políticas nos Programas de Pós-Graduação brasileiros: um mapa das teses e dissertações. Revista de Estudios Teóricos y Epistemológicos en Política Educativa, v. 3, p. 1-29, 2018.

LOPES, Alice Casimiro. Base curricular, saberes, culturas e ciências: construção do currículo interdisciplinar na escola. In: ENCONTRO NACIONAL ENSINO E INTERDISCIPLINARIDADE (ENACEI), 2.; SEMINÁRIO DE AVALIAÇÃO DE CURSOS DE PEDAGOGIA (SEMAPED), 2., Mossoró. Anais... Rio Grande do Norte: Mossoró, 2019. 68-69 p.

LOPES, Alice Casimiro. Itinerários formativos na BNCC do Ensino Médio: identificações docentes e projetos de vida juvenis. Revista Retratos da Escola, Brasília, DF, v. 13, n. 25, p. 59-75, jan./maio 2019.

LOPES, Alice Casimiro. Teorias pós-críticas, política e currículo. Educação, Sociedade \& Culturas, Portugal, n. $39,2013$.

MAINARDES, Jefferson. Abordagem do ciclo de políticas: uma contribuição para a análise de Políticas educacionais. Educação e Sociedade, Campinas, v. 27, n. 94, p. 47-69, jan./abr. 2006a.

MAINARDES, Jefferson. A abordagem do ciclo de políticas e suas contribuições para a análise da trajetória de políticas educacionais. Atos de pesquisa em educação, v. 1, n. 2, p. 94-105, maio/ago. $2006 \mathrm{~b}$.

MOORE, Alan. Recognising desire: a psychosocial approach to undersanding education policy implementation and effect. Oxford Review of Education, v. 32, n. 4, 2006.

RIZVI, Fazal; KEMMIS, Stephen. Dilemmas of reform. Geelong Vic: Deakin University Press, 1987.

OLIVEIRA, Meyre Ester Barbosa. A política nos estudos curriculares: da centralidade do Estado à circularidade das políticas. In: BANDEIRA, H. M.M.; IBIAPINA, I. M. L. M.; ALLOUFA, J. M. L. (org.). Pesquisa em educação: unidade na diversidade. 1. ed. Fortaleza: Imprece, 2015. v. 1. p. 36-44.

SANTOS, Geniana; BORGES, Veronica; LOPES, Alice Casimiro. Formação de Professores e Reformas Curriculares: Entre Projeções e Normatividade. Linhas Críticas, Brasília, DF, v. 2, 2019. 
